\title{
The Thermal Demands of Flood Rescue and Impacts on Task Performance
}

Michael J. Tipton ${ }^{\mathrm{a}}$, Cristian Abelairas-Gómez ${ }^{\mathrm{b}}$, Adrian Mayhew ${ }^{\mathrm{c}}$, Gemma S. Milligan ${ }^{\mathrm{a}}$

\section{*Corresponding author}

${ }^{a}$ Extreme Environments Laboratory, Department of Sport and Exercise Science, University of Portsmouth, Spinnaker Building, Cambridge Road, Portsmouth, Hants, PO1 2ER, UK. (e) michael.tipton@port.ac.uk; gemma.milligan@port.ac.uk*

${ }^{\mathrm{b}}$ CLINURSID research group and Faculty of Education Sciences, Universidade de Santiago de Compostel, Praza do Obradoiro, s/n, 15782 Santiago de Compostela (Spain). (e) cristianabelairasgomez@gmail.com

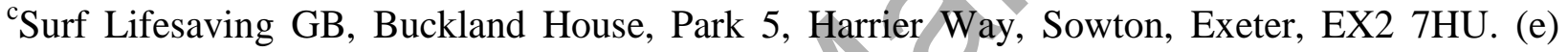
AMayhew@slsgb.org.uk

Word count: 4652 


\title{
The Thermal Demands of Flood Rescue and Impacts on Task Performance
}

\begin{abstract}
Objective: To determine the thermal demand of simulated Flood Rescue tasks and impacts on performance. Methods: Ten participants undertook two simulations: 'Cold' $\left(4^{\circ} \mathrm{C}\right)$-participants stood in knee height moving water $\left(4.8 \mathrm{~km} \cdot \mathrm{h}^{-1}\right)$, with simulated wind and rain for $60 \mathrm{~min}$. 'Warm' $\left(20^{\circ} \mathrm{C}\right)$-participants performed $6 \times 7 \mathrm{~min}$ walking in knee height moving water $\left(3.2 \mathrm{~km} \cdot \mathrm{h}^{-1}\right)$, pulling 10kg. Grip strength, manual dexterity, and jump height were measured pre and post. Results: The cold resulted in cooling of the great toe and finger $\left(9.98[0.84]^{\circ} \mathrm{C}\right.$ and $10.38[8.21$ $12.1]^{\circ} \mathrm{C}$ respectively). Jump height, manual dexterity and grip strength fell by $20 \%, 22 \%$ and $\sim 13 \%$ respectively. In the 'Warm': heart rates were 157 (19)b. min ${ }^{-1}$, oxygen consumption 30.62 (7.83)mL. $\mathrm{kg}^{-1} \cdot \mathrm{min}^{-1}$, and sweat loss $1.06(0.31) \mathrm{L}$. There were no differences in the physical tests. Conclusion: Flood Rescue represents significant, but different, challenges. Remaining static in the cold resulted in peripheral neuromuscular cooling, whilst exercising in the warm resulted in significant thermal challenge.
\end{abstract}

Keywords: Fitness, Flowing water, Personal Protective Equipment, Technician

\section{Practitioner Summary}

Little is known about the physical requirements, thermal profiles and optimum personal protective equipment for flood rescue. Flood rescue represents significant challenges. In the cold, emergency responders may be incapacitated by peripheral cooling. In the heat, they may be incapacitated by heat-related exhaustion. Consideration should be given to these risks. 


\subsection{Introduction}

In comparison with the evidence based research that underpins other scenarios involving rescue personnel and their personal protective equipment (PPE), relatively little is known about the physical requirements, thermal profiles and optimum PPE for flood rescue (FR). FR can occur in a range of thermal conditions and PPE is required to be worn, challenging the thermal status of the rescuer. Cooling and heating in PPE during partial immersion (i.e.to the knee) in flowing water as occurs in FR is under researched. Convective cooling in water is maximised in water flow rates between $0.5 \mathrm{~m} . \mathrm{s}^{-1}$ and $1.3 \mathrm{~m} . \mathrm{s}^{-1}\left(2.88 \mathrm{~km} \cdot \mathrm{h}^{-1}\right.$ and $4.68 \mathrm{~km} \cdot \mathrm{h}^{-1}$; (Tipton \& Golden, 1998)). Cooling of the superficial nerves and muscles, in particular of the limbs, quickly reduces functions like grip strength and manual dexterity (Tipton \& Vincent, 1988). Nerve block can occur after 15 minutes in water at $15{ }^{\circ} \mathrm{C}$ reducing power output of a muscle by $3 \%$ per ${ }^{\circ} \mathrm{C}$ fall in its temperature (Basbaum, 1973; Clarke, Hellon, \& Lind, 1958; Douglas \& Malcolm, 1955).

Due to FR responder's proximity to contaminated water, teams are required to wear PPE even in warm simulations. Thus increasing the potential for hyperthermia, the signs and symptoms of which range from light-headedness to unconsciousness and heat stroke (Tipton, 2015). If all of the heat produced by the body is prevented from passing to the environment due to clothing, a fatal level of heat storage can be reached in about 20 minutes when working moderately (Noakes, 1991).

Given the above, there is a need to consider the potential thermal demands of FR and the potential consequences for the performance of the physical tasks associated with FR. To undertake such an investigation, it is important to establish the critical tasks associated with FR 
and characterise them in terms of their technique, criticality, frequency, intensity and duration. Internationally recognised methodologies for undertaking a task analysis have been recommended (Tipton, Milligan, \& Reilly, 2013). This is achieved by task analysis which involves: reviewing standard operating procedures; direct observation; interviews and discussion groups with subject matter experts (SME) (Blacker et al., 2015; Milligan, Reilly, Zumbo, \& Tipton, 2016; Reilly, Gebhardt, Billing, Greeves, \& Sharp, 2015; Stevenson, Siddall, Turner, \& Bilzon, 2016; Tipton et al., 2013).

This study investigated the thermal demands of FR and the consequences for physical task performance. The simulations chosen were based on typical 'Cold' and 'Warm' conditions as defined by SME. It was hypothesised that remaining static in the 'Cold' simulation would result in cooling resulting in significant decrements in physical performance, whilst exercising in the 'Warm' simulation would result in significant increases in deep body temperature and physical effort during the simulation.

\subsection{Methods}

\subsection{Participants}

Written informed consent was obtained from the participants before starting the study and favourable ethical opinion was granted by the Science Faculty Research and Ethics committee (SFEC 2017-110). On the basis of a power calculation, ten male participants volunteered and took part in the study (mean (SD) Age, 37 (11) years; Height, $179.44(6.11) \mathrm{cm}$; Mass, 85.80 (7.12) $\mathrm{kg}$ ). Sum of Skinfolds, $101.14(48.36) \mathrm{mm}$. They were recruited from FR teams 
throughout the UK ( $n=7$, minimum experience 2 years) and members of the University $(n=3)$ who had been familiarised with wading through moving water.

\subsection{Procedures}

On arrival to the laboratory (Air Temperature - 19.07 [1.63] ${ }^{\circ} \mathrm{C}$; Barometric Pressure - 1012 [11] mbar; Humidity - 64 [6] \%) participants' height to the nearest $0.1 \mathrm{~cm}$ (Seca Ltd, Leicester, UK), nude mass to the nearest $0.05 \mathrm{~kg}$ (Model B150S Sartorious, UK), and skinfold thickness at eight sites (biceps, triceps, subscapular, iliac crest, supraspinale, abdominal, front thigh, medial calf, Note: all eight sites were summed), were measured. Pre- and post-physical performance tests were performed in air in the laboratory involved: a counter movement jump (CMJ), maximum grip strength, and a timed manual dexterity task (unscrew and re-screw a nut and bolt). All preand post-tests were undertaken wearing flood rescue PPE (SafeQuip, UK) which included: a long sleeve thermal vest and trousers; dry suit; gloves, steel toe capped boots; thermal socks; helmet; helmet liner ('Cold' simulation only) and a personal flotation device. The total mass of the kit was $9.25 \mathrm{~kg}$. Participants then undertook two simulations, in a controlled environmental laboratory, based on advice from SME. The SME consisted of three experienced ( $>5$ years undertaking flood rescue) FR emergency responders, who were proficient in performing, training, and leading flood rescues, from Surf Life Saving GB, and the Royal National Lifeboat Institution. Two simulations were selected based on the activities likely to be undertaken during a rescue performed on a typical cold and hot day in the UK. Experimental air and water temperatures were based on available data from the UK Met Office 2016 to 2017. The flume flow rates were based on the Flood Rescue National Enhancement Project (Defra, 2012) which 
stipulates a technician should be able to demonstrate wading up to class 2 swift water (i.e. water moving faster than walking pace is too rapid for a wading to take place).

These simulations were performed at least 24 hours apart in a thermostatically controlled climatic chamber containing a swimming flume:

i. The 'Cold' simulation required participants to stand immersed to the knee in the swimming flume with moving water flowing at a rate of $4.8 \mathrm{~km} \cdot \mathrm{h}^{-1}$, with simulated rain (a shower head place directly above the participant) for $60 \mathrm{~min}$ (Figure 1). Air temperature, water temperature wind speed and humidity were set to $4{ }^{\circ} \mathrm{C}, 7.7{ }^{\circ} \mathrm{C}, 16$ $\mathrm{km} \cdot \mathrm{h}^{-1}$ and $80 \%$ respectively. Due to the constant addition of water to the flume from the simulated rain, water was removed at regular intervals to keep it at knee height.

\section{INSERT FIGURE 1 HERE}

ii. The 'Warm' simulation consisted of six 7 min stages with 3 min rest. Participants were immersed to approximately knee height and walked from one end of the swimming flume to the other $(3.30 \mathrm{~m})$ at a speed of $2.16 \mathrm{~km} \cdot \mathrm{h}^{-1}$, in water flowing at $3.2 \mathrm{~km} \cdot \mathrm{h}^{-1}$. Participants walked into the flow of water pulling a $10 \mathrm{~kg}$ load attached to a 1:1 pulley system (Figure 2). On reaching the end of the flume participants turned around and walked with the flow of water, controlling the release of the $10 \mathrm{~kg}$ (100 N static force). The load represented pulling a rescue boat. Air temperature, water temperature humidity, wind speed and radiant heat load were $20^{\circ} \mathrm{C}, 15.6^{\circ}, 40 \%, 0 \mathrm{~km} \cdot \mathrm{h}^{-1}$, and $500 \mathrm{~W} \cdot \mathrm{m}^{-2}$ respectively. 


\section{INSERT FIGURE 2 HERE}

\subsection{Measurements}

The measurements taken were selected as they represented the physical parameters of the tasks FR emergency responders might be expected to perform following a rescue.

2.3.1 Pre and Post exposure tests (collected immediately before and after each simulation).

\subsubsection{Calculation of Sweat Loss}

Nude body mass was measured to $0.01 \mathrm{~kg}$ (Ohaus, US) on arrival to the laboratory and following the simulations and post-test measures. Water consumption was monitored and factored into sweat loss calculations (Pre mass - Post mass[+ water consumption]).

2.3.1.2 Counter Movement Jump (CMJ) - used to simulate the activation of the muscles required to get into a rescue boat. The participant, wearing full PPE, stood as still as possible on the mat (Takei, Japan) with weight evenly distributed over both feet. Hands were placed on the hips, and stayed there throughout the test. The participant squatted down to a self-selected depth then immediately jumped vertically as high as possible, landing back on the mat on both feet at the same time. This was repeated three times with $30 \mathrm{~s}$ rest between each jump. The best result (height jumped, cm) of the three attempts was recorded. 
2.3.1.3 Grip Strength - used to simulate the activation of the muscles used in tasks such as casualty handling and evacuation. Grip strength was measured using a Precision Dynamometer G100 (Biometrics Ltd, Gwent, UK) accurate to $0.1 \mathrm{~kg}$. Maximum grip strength tests were undertaken three times for each hand, allowing $30 \mathrm{~s}$ rest between tests of the same hand (Douris, Mckenna, Madigan, Cesarski, \& Lu, 2003). The dynamometer was zeroed before each test; the elbow was at 90 degrees. The hand did not tilt, rest on the leg or table, and grip was a maximal squeeze.

2.3.1.4 Manual Dexterity - fine motor tasks such as tying knots. To represent a fine motor skill task, participants were asked to unscrew and re-screw a large nut and bolt using their hands (Figure 3). The total time taken to fully unscrew and re-screw the nut was recorded.

\subsubsection{Variables monitored during the exposures}

2.3.2.1 Deep body temperature. Tre was measured with a thermistor (Sharktooth ${ }^{\circledR}$, MIE, UK) inserted $10 \mathrm{~cm}$ beyond the anal sphincter. The Tre data were obtained via telemetry (Sharktooth $\left.{ }^{\circledR}, \mathrm{MIE}, \mathrm{UK}\right)$, displayed in real time and recorded.

2.3.2.2 Skin temperature and heart rate. Skin temperature (Tsk) of the biceps, chest, thigh, shin, middle finger, great toe (Sharktooth $\left.{ }^{\circledR}, \mathrm{MIE}, \mathrm{UK}\right)$ and heart rate (HR, Sharktooth $\left.{ }^{\circledR}, \mathrm{MIE}, \mathrm{UK}\right)$, were collected, displayed in real time and recorded continuously by telemetry (Sharktooth $囚$, MIE, UK). Weighted mean skin temperature (Tsk) was calculated according using $0.3 *$ (Biceps + Chest $)+0.2 *($ Thigh + Shin $)($ Ramanathan, 1964) . 
2.3.2.3 Oxygen consumption. Expired gas samples were obtained with the participants seated at rest for 5 minutes prior to entering the climatic chamber using a Douglas Bag. Once in the climatic chamber expired gas were sampled for one minute. Samples were taken during the $5^{\text {th }}$ and $55^{\text {th }}$ minute in the 'Cold' simulation and $15^{\text {th }}$ and $55^{\text {th }}$ minute in the 'Warm' simulation as not to interfere with the activity of the participant. The gas sample was analysed for oxygen and carbon dioxide factions (Rapidox 1100L, Cambridge Sensotec, UK) and the volume (Dry Gas Metre 230V, HaB Direct, UK) quantified in order to calculated oxygen consumption (STPD (Weir, 1949)).

2.3.2.4 Subjective responses. Rating of Perceived Exertion (RPE, Borg, Hassmén, \& Lagerström, 1987), thermal comfort and sensation (Davey, Reilly, Newton, \& Tipton, 2007) and skin wettedness (Filingeri, Fournet, Hodder, \& Havenith, 2014) were used to quantify subjective perceptions of exertion and thermal comfort placed on the participant during both simulations. At the end of each minute, the participants were asked to provide an RPE using the CR-10 RPE scale. Participants reported thermal comfort, sensation and skin wettedness on sliding scales from 'very uncomfortable' to 'very comfortable', 'very cold' to 'very hot' and 'very dry' to 'very wet' respectively.

\subsection{Data Analysis}

Data were statistically analysed using IBM SPSS 24.0 for Windows (SPSS Inc, Chicago, IL). Tests of normality were conducted to assess, if the data were parametric using Skewness and Kurtosis. Data are presented as mean (SD) or median (range) as appropriate. Paired samples ttests were conducted to determine if any significant differences existed pre and post exposure. 
Effect sizes were calculated using Cohen's $d$ Statistic (Cohen, 1988). Non-parametric data were analysed using Wilcoxon Signed-rank test. Effect sizes were calculated using the Pearson's (r) statistic (Field, 2013).

\subsection{Results}

\subsection{Cold Simulation}

The temperature at the great toe fell significantly $\left(\mathrm{t}_{(9)}=9.626 ; \mathrm{p}<0.001 ; d=3.94\right)$ from 26.92 $(6.02){ }^{\circ} \mathrm{C}$ to $9.98(0.84){ }^{\circ} \mathrm{C}$ (Figure 1). Similarly median (range) finger temperatures fell significantly $\left(\mathrm{Z}_{(9)}=-2.803 ; \mathrm{p}=0.005 ; r=-0.72\right)$ from $34.45(14.00){ }^{\circ} \mathrm{C}$ to $10.38(3.89){ }^{\circ} \mathrm{C}$ (Figure 4). Tsk temperature fell significantly $\left(\mathrm{t}_{(9)}=10.979 ; \mathrm{p}<0.001 ; \hat{d}=0.48\right)$ from $34.76(1.22){ }^{\circ} \mathrm{C}$ to $27.29(2.19){ }^{\circ} \mathrm{C}$.

\section{INSERT FIGURE 4 HERE}

Tre did not change significantly $\left(\mathrm{t}_{(7)}=0.710 ; \mathrm{p}=0.500 ; d=0.17\right)$ from the start of the immersion (37.55 (0.45) $\left.{ }^{\circ} \mathrm{C}\right)$ to 60 minutes $\left(37.48(0.36){ }^{\circ} \mathrm{C}\right)$ (Figure 2). Heart rate was significantly higher $(p<0.05)$ at time points $0,5,10$ and 15 compared to time point 60 . From time point 20 to 60 there were no significant differences ( $p>0.05$ ) in HR (Figure 5).

\section{INSERT FIGURE 5 HERE}

Oxygen consumption rose significantly $\left(\mathrm{t}_{(9)}=-3.402 ; \mathrm{p}=0.008 ; d=-0.96\right)$ from the $5^{\text {th }}$ minute (7.56 (1.88) $\left.\mathrm{mL} \cdot \mathrm{kg}^{-1} \cdot \mathrm{min}^{-1}\right)$ to the $55^{\text {th }}$ minute $\left(10.04(3.13) \mathrm{mL} \cdot \mathrm{kg}^{-1} \cdot \mathrm{min}^{-1}\right)$ (Figure 6). 


\section{INSERT FIGURE 6 HERE}

Figure 7 shows the subjective responses recorded in both simulations. Participants did not find the 'Cold' simulation physical demanding, but did report feeling very cold and uncomfortable by the end.

\section{INSERT FIGURE 7 HERE}

Jump height fell significantly $\left(\mathrm{t}_{(9)}=7.693 ; \mathrm{p}<0.001 ; d=0.91\right)$ by $20 \%$. Manual dexterity significantly $\left(\mathrm{Z}_{(9)}=-2.599 ; \mathrm{p}=0.009 ; r=-0.82\right)$ deteriorated by $22 \%$ and grip strength fell significantly $\left(\mathrm{t}_{(9)}=4.552 ; \mathrm{p}=0.001 ; d=1.14\right)$ by $14 \%$ in the dominant hand and by $13 \%$ in the non-dominant $\left(\mathrm{t}_{(9)}=4.859 ; \mathrm{p}=0.001 ; d=0.87\right)($ Table 1$)$.

\section{INSERT TABLE 1 HERE}

\subsection{Warm Simulation}

Initially participants were asked to work continuously for 60 minutes, walking at $2.16 \mathrm{~km} . \mathrm{h}^{-1}$ in water flowing at $4.8 \mathrm{~km} \cdot \mathrm{h}^{-1}$; however, the first participant found this impossible and following 10 minutes of exercise was exhausted and had a predicted time of $\sim 45$ minutes to reach a deep body temperature of $40{ }^{\circ} \mathrm{C}$. As a consequence, the requirements were modified as described in the methodology. By the end of the exposure to the revised simulations, average heart rates were 157 (19) $\mathrm{b} \cdot \mathrm{min}^{-1}$ (Figure 8 ), this still represented $87 \%$ of predicted average maximum heart rate. Oxygen consumption averaged $30.62(7.83) \mathrm{mL} \cdot \mathrm{kg}^{-1} \cdot \mathrm{min}^{-1}$ during the final 5 minutes (Figure 6). 


\section{INSERT FIGURE 8 HERE}

Participants reported feeling very warm and uncomfortable with a high skin wittedness (Figure 4). The level of discomfort reported was similar in both simulations, but for different reasons. In the cold it was cold extremities and discomfort due to mild shivering. In the heat is was high deep body temperature and perceptions mot probably related to central fatigue. Average sweat loss was $1.06(0.31) \mathrm{L}$ following exposure. Tre significantly $\left(\mathrm{t}_{(7}=-7.434 ; \mathrm{p}<0.001 ; d=-2.95\right)$ increased for the start to the end of the simulation (Figure 9).

\section{INSERT FIGUE 9 HERE}

Jump height, grip strength, manual dexterity did not change significantly $(\mathrm{p}>0.05)$ pre and post exposure (Table 2).

INSERT TABLE 2 HERE

\subsection{Discussion}

This was the first investigation into the physical and thermal demands associated with two typical FR simulations. The simulations observed were those regarded by subject matter experts as 'Cold' and 'Warm'; it is likely that most FR simulations fall between these conditions. The experienced FR emergency responders who volunteered for the study reported that the simulations, including workload in the 'Warm' simulation were realistic. The results demonstrate significant physical impairment following both simulations but the nature of that impairment, as hypothesised, differed. 
In the 'Cold' simulation, the primary problem was associated with peripheral neuromuscular impairment resulting in physical incapacitation on tests requiring muscle function. The reduction in muscle function (hand and leg) ranged between $13-22 \%$ after one hour in 'Cold' simulation. This reduction is due to the direct effect of cooling on neuromuscular function (Castellani \& Tipton, 2016). Maximal dynamic strength, power output, jumping and sprinting performance are reduced by 4 to $6 \%$ per ${ }^{\circ} \mathrm{C}$ reduction in muscle temperature down to $30{ }^{\circ} \mathrm{C}$ (Bergh \& Ekblom, 1979). At nerve temperatures below $20{ }^{\circ} \mathrm{C}$, nerve conduction is slowed and action potential amplitude is decreased (Douglas \& Malcolm, 1955). Nerve block may oceur after exposure to a local temperature of between 5 and $15^{\circ} \mathrm{C}$ for 1-15 minutes (Basbaum, 1973; Clarke et al., 1958).

The implication for FR is that with time in cold conditions emergency responders may find it increasingly difficult to perform fine motor skills e.g. untying ropes and tasks where leg power is required e.g. jumping into/manoeuvring a rescue boat. These decrements in performance should be taken into consideration when determining the physical requirements needed by FR emergency responders. Typically, selection criteria are determined when individuals are thermoneutral, therefore a technician just passing a required physical standard when normothermic may fail to achieve that standard when cold. This has implications for operational capability during rescues, such considerations have been recognised in other occupations (Baumgartner, Gruse, Flerlage, \& Hanley, 2017).

On a health-related issue, it is worth noting that the peripheral skin temperatures recorded during the cold condition (circa $10{ }^{\circ} \mathrm{C}$ ) and the circumstances of that condition (dependent limb, compressed tissues due to footwear and immersion) are very close to those associated with the 
acquisition of a non-freezing cold injury (NFCI), particularly when exposure times are extended (Francis \& Golden, 1985). The pathogenesis and pathology of NFCI are poorly understood, but the life-long consequences of this injury are well-recognised as: cold sensitivity, persistent intractable pain and hyperhidrosis (Golden, Francis, Gallimore, \& Pethybridge, 2013). NFCI is a major cause of disability compensation claims within the military ("Lessons from history: morbidity of cold injury in the Royal Marines during the Falklands Conflict of 19822017," 2018) In the 'Warm' simulation, despite being immersed to mid-thigh in flowing cool water, the combination of exercise-related heat production and warm ambient conditions resulted in an uncompensable increase in deep body temperature (Figure 6). This increase, plus the high heart rates, oxygen consumptions and ratings of perceived exertion all suggest that in this condition people were working near their maximum capability. Having introduced the work-rest schedules to the protocol, the subsequent oxygen consumptions and heart rate values reported in the 'Warm' FR simulation still represented 'extremely heavy work' (Åstrand, Rodahl, Dahl, \& Strømme, 2003). The metabolic requirements experienced during this simulation (30.62 (7.83) $\left.\mathrm{mL} \cdot \mathrm{kg}^{-1} \cdot \mathrm{min}^{-1}\right)$ are comparable to those reported for mud rescue technicians (32.85 (5.79) mL.kg${ }^{1} \cdot \mathrm{min}^{-1}$ ) pulling a rescue sled weighing $61 \mathrm{~kg}$ across estuary mud at a median (range) speed of $2.61(0.56) \mathrm{km} \cdot \mathrm{h}^{-1}$ (Milligan, House, \& Tipton, 2017).

It is important to consider what percentage of an individual's maximum capacity performing a task such as FR should represent. When determining this percentage, consideration should be given to the duration of the task and its importance. For example, it is permissible to allow employees to work at maximum capacity for short durations, followed by rest, or in an emergency (Goldman, 2000). However, it is not thought acceptable to expect individuals to 
routinely work at their maximum capacity, to do so will result in fatigue, with a consequent decrement in performance and a potential increase in the likelihood of accidents (e.g. trips and falls (Parijat \& Lockhart, 2008)). Louhevaara Louhevaara, Smolander, Korhonen, and Tuomi (1986) Goldman (2000) suggest that individuals working for approximately one hour could do so if the task represents no more than $60 \%$ of their maximum oxygen uptake $\left(\dot{V} \mathrm{O}_{2 \max }\right)$. On the basis of the data collected in the present study, this would mean FR emergency responders would require a $\dot{V} \mathrm{O}_{2 \max }$ of approximately $51 \mathrm{~mL} \cdot \mathrm{kg}^{-1} \cdot \mathrm{min}^{-1}$. The percentage of sustainable $\dot{V} \mathrm{O}_{2 \max }$ (calculated based on body mass not including PPE) for intermittent work has not been documented, therefore thought needs to be given to specific work-rest scheduling of FR activities in the heat, and a consequent aerobic fitness requirements.

In 'Warm' conditions, the physical demand of work is compounded by the additional cardiovascular demand of high body temperatures, this combination can lead to a switch to anaerobic metabolism and early heat exhaustion (Cheuvront, Kenefick, Montain, \& Sawka, 2010; Ely, 2010). An unchecked increase in deep body temperature can result in heat exhaustion at a deep body temperature of about $40^{\circ} \mathrm{C}$ (Nybo \& Nielsen, 2001) and heat stroke, a critical medic condition, at a deep body temperatures of $>40.5^{\circ} \mathrm{C}$ (Tipton, 2015). The proximity of the 'Warm' simulations to the circumstances necessary to produce heat exhaustion was exemplified by the first participant, an experienced FR technician, who found it impossible to undertake continuous work for more than 10 minutes; his increase in deep body temperature during this period can be extrapolated to predict heat exhaustion in 43 minutes and heat stroke in 60 minutes (assuming he was able to continue work). The changes in the experimental design necessitated by this response provides a clue as to how the risk of heat illness can be managed with FR emergency responders. This includes the expedient use of work-rest schedules, plus hydration 
strategies, cooling strategies during rest periods and wearable physiological monitoring equipment. These interventions should help avoid heat-related health problems and optimize FR technician performance (Notley, Flouris, \& Kenny, 2018; Tipton, 2015).

\subsection{Conclusions}

It is concluded that FR in both 'Cold' and 'Warm' simulations, reported here, represent significant, but different challenges. In the cold, emergency responders may be incapacitated by peripheral cooling, in the heat, they may be incapacitated by heat-related exhaustion. The hypotheses are accepted. Consideration should be given to elucidating and expanding these initial findings as well as exploring different methods of mitigating the risks identified.

6.0 Acknowledgments - Paddy Morgan (Surf Lifesaving GB), Grant Walkey (Royal National Lifeboat Institute), Geoff Long (University of Portsmouth), Danny White (University of Portsmouth), David Lane (ProRescue) and Joshua Robinson (University of Portsmouth).

7.0 Funding details \& Declaration of Interest: This research did not receive any specific grant from funding agencies in the public, commercial, or not-for-profit sectors. The authors have no conflict of interest. 


\subsection{References}

Åstrand, P.O., Rodahl, K., Dahl, H. A., \& Strømme, S. B. (2003). Textbook of Work Physiology: Physiological Bases of Exercise: Human Kinetics.

Basbaum, C. B. (1973). Induced hypothermia in peripheral nerve: electron microscopic and electrophysiological observations. Journal of Neurocytology, 2(2), 171-187. doi.org/10.1007/BF01474719

Baumgartner, N., Gruse, M., Flerlage, E., \& Hanley, Z. (2017). USAF occupationally specific, operationally relevant physical fitness tests and standards: Effects of mission and environmental stressors. Journal of Science and Medicine in Sport, 20, S128. doi.org/10.1016/j.jsams.2017.09.471

Bergh, U., \& Ekblom, B. (1979). Influence of muscle temperature on maximal muscle strength and power output in human skeletal muscles. Acta Physiologica Scandinavica, 107(1), 33-37. doi.org/10.1111/j.1748-1716.1979.tb06439.x

Blacker, S. D., Rayson, M. P., Wilkinson, D. M., Carter, J. M., Nevill, A. M., \& Richmond, V. L. (2015). Physical employment standards for UK fire and rescue service personnel. Occupational Medicine, 66(1),38-45. doi.org/10.1093/occmed/kqv122

Borg, G., Hassmén, P., \& Lagerström, M. (1987). Perceived exertion related to heart rate and blood lactate during arm and leg exercise. European Journal of Applied Physiology and Occupational Physiology, 56(6), 679-685. doi.org/10.1007/BF00424810

Castellani, J. W., \& Tipton, M. J. (2016). Cold stress effects on exposure tolerance and exercise performance. Comprehensive Physiology, 6, 443-469. doi.org/10.1002/cphy.c140081

Cheuvront, S. N., Kenefick, R. W., Montain, S. J., \& Sawka, M. N. (2010). Mechanisms of aerobic performance impairment with heat stress and dehydration. Journal of Applied Physiology, 109(6), 1989-1995. doi.org/10.1152/japplphysiol.00367.2010 
Clarke, R. S., Hellon, R. F., \& Lind, A. R. (1958). The duration of sustained contractions of the human forearm at different muscle temperatures. Journal of Physiology, 143(3), 454-473.

Cohen, J. (1988). Statistical power analysis for the behavioural sciences: Hillsdale, NJ: erlbaum.

Davey, S., Reilly, T., Newton, M., \& Tipton, M. (2007). The reproducibility and validity of visual analogue scales (VAS) that assess thermal perceptions in stable and dynamic, asymmetric environments. Environmental Ergonomics XII, 117.

Defra. (2012). Flood Rescue National Enhancement Project - Flood Rescue Concept of Operations.

Douglas, W. W., \& Malcolm, J. L. (1955). The effect of localized cooling on conduction in cat nerves. Journal of Physiology, 130(1), 53-71. doi.org/10.1113/jphysiol.1955.sp005392

Douris, P., Mckenna, R., Madigan, K., Cesarski, B., \& Lu, M. (2003). Recovery of maximal isometric grip strength following cold immersion. Journal of Strength and Conditioning Research, 17(3), 509-513. doi.org/10.1519/00124278-200308000-00014

Ely, B. R., Cheuvront, S.N., Kenefick, R.W. and Sawka, M.N. (2010). Aerobic performance is degraded, despite modest hypothermia, in hot environments. ARMY RESEARCH INST OF ENVIRONMENTAL MEDICINE NATICK MA THERMAL AND MOUNTAIN MEDICINE DIVISION, .

Field, A. (2013). Discovering statistics using IBM SPSS statistics: Sage.

Filingeri, D., Fournet, D., Hodder, S., \& Havenith, G. (2014). Why wet feels wet? A neurophysiological model of human cutaneous wetness sensitivity. Journal of Neurophysiology, 112(6), 1457-1469. doi.org/10.1152/jn.00120.2014

Francis, T., \& Golden, F. (1985). Non-freezing cold injury: the pathogenesis. Journal of the Royal Naval Medical Service, 71(1), 3. 
Golden, F. S. C., Francis, T. J. R., Gallimore, D., \& Pethybridge, R. (2013). Lessons from history: morbidity of cold injury in the Royal Marines during the Falklands Conflict of 1982. Extreme Physiology \& Medicine, 2(1), 23. doi.org/10.1186/2046-7648-2-23

Goldman, R. F. (2000). Heat stress in industrial protective encapsulating garments. In L. S. P. Martin W.F (Ed.), Protecting Personnel at Hazardous Waste Sites (pp. 258-315). USA: Butterworth-Heinemann.

Lessons from history: morbidity of cold injury in the Royal Marines during the Falklands Conflict of 19822017. (2018). Lawyer Monthly. Avaliable from https://goo.gl/rhMfcb

Louhevaara, V., Smolander, J., Korhonen, O., \& Tuomi, T. (1986). Maximal working times with a self-contained breathing apparatus. Ergonomics, 29(1), 77-85. doi.org/10.1080/00140138608968242

Milligan, G. S., House, J. R., \& Tipton, M. J. (2017). The physiological demand of pulling a rescue sled across the mud and the impact experience has on this task. Work, 56(2), 239245. doi.org/10.3233/WOR-172487

Milligan, G. S., Reilly, T. J., Zumbo, B. D., \& Tipton, M. J. (2016). Validity and reliability of physical employment standards. Applied Physiology Nutrition and Metabolism, 41(6 Suppl 2), S83-91. doi: 10.1139/apnm-2015-0669 doi.org/10.1139/apnm-2015-0669

Noakes, T. D., Myburgh, K. H., Lang, L., Lambert, M., Schall, R. . (1991). Metabolic rate, not percent dehydration, predicts rectal temperature in marathon runners. . Medicine and Science in Sports and Exercise, 23(4), 443-449. doi.org/10.1249/00005768-19910400000009

Notley, S. R., Flouris, A. D., \& Kenny, G. P. (2018). On the use of wearable physiological monitors to assess heat strain during occupational heat stress. Applied Physiology Nutrition and Metabolism, 43(9), 869-881. doi.org/10.1139/apnm-2018-0173 
Nybo, L., \& Nielsen, B. (2001). Hyperthermia and central fatigue during prolonged exercise in humans. Journal of Applied Physiology, 91(3), 1055-1060. doi.org/10.1152/jappl.2001.91.3.1055

Parijat, P., \& Lockhart, T. E. (2008). Effects of quadriceps fatigue on the biomechanics of gait and slip propensity. Gait Posture, 28(4), 568-573. doi.org/10.1016/j.gaitpost.2008.04.001

Ramanathan, N. (1964). A new weighting system for mean surface temperature of the human body. Journal of Applied Physiology, 19(3), 531-533. doi.org/10.1152/jappl.1964.19.3.531

Reilly, T. J., Gebhardt, D. L., Billing, D. C., Greeves, J. P., \& Sharp, M. A. (2015). Development and Implementation of Evidence-based Physical Employment Standards: Key Challenges in the Military Context. The Journal of Strength \& Conditioning Research, 29, S28-S33. doi.org/10.1519/JSC. 0000000000001105

Stevenson, R. D., Siddall, A. G., Turner, P. F., \& Bilzon, J. L. (2016). A task analysis methodology for the development of minimum physical employment standards. Journal of Occupational and Environmental Medicine, 58(8), 846-851. doi.org/10.1097/JOM.0000000000000812

Tipton, M. (2015). Extreme temperature sport and exercise medicine. In M. L. Greg Whyte, Clyde Williams (Ed.), ABC of Sports Medicine (pp. 67-75). Chichester: John Wiley \& Sons Ltd. (Reprinted from: 2).

Tipton, M., \& Golden, F. (1998). Immersion in cold water: effects on performance and safety Oxford textbook of sports medicine: Oxford University Press.

Tipton, M., Milligan, G., \& Reilly, T. (2013). Physiological employment standards I. Occupational fitness standards: objectively subjective? European Journal of Applied Physiology, 113(10), 2435-2446. doi.org/10.1007/s00421-012-2569-4 
Tipton, M., \& Vincent, M. (1988). The effects of cold immersion and hand protection on grip strength. Aviation, Space, and Environmental Medicine, 59, 738-741.

Weir, J. d. V. (1949). New methods for calculating metabolic rate with special reference to protein metabolism. The Journal of Physiology, 109(1-2), 1-9. doi.org/10.1113/jphysiol.1949.sp004363

\section{Tables}

Table 1. Mean (SD) physical assessment data (Counter movement jump, Manual dexterity, Grip strength of the dominant and non-dominant hand) pre and post the 'Cold' flood rescue simulation $(n=10)$.

\begin{tabular}{lrr}
\hline \multicolumn{1}{c}{ Physical Assessment } & Pre exposure & Post exposure \\
\hline Counter movement jump (cm) & $39.10(9.24)$ & $31.20(8.12)^{* *}$ \\
\hline Manual dexterity (s)* & $46(22)$ & $58(31)^{\wedge}$ \\
\hline Grip strength - dominant (kg) & $49.40(6.95)$ & $42.24(5.53)^{* *}$ \\
\hline Grip strength - non-dominant (kg) & $47.03(6.67)$ & $41.28(6.56)^{* *}$ \\
\hline
\end{tabular}

\footnotetext{
*Data presented as median (range); ** significant difference $\mathrm{p}<0.001 ;{ }^{\wedge}$ significant difference $\mathrm{p}<0.05$
} 
Table 2. Mean (SD) physical assessment data (Counter movement jump, Manual dexterity, Grip strength of the dominant and non-dominant hand) pre and post the 'Warm' flood rescue simulation $(\mathrm{n}=9)$.

\section{Physical Assessment}

Pre exposure

\section{Post exposure}

$\begin{array}{lll}\text { Counter movement jump (cm) } & 36.75(7.85) & 37.88(8.27)\end{array}$

Manual dexterity (s)* $40(24)$ $37(20)$

Grip strength - dominant (kg) $47.63(5.30)$ $45.30(6.73)$

Grip strength - non-dominant (kg) $45.30(6.73)$ $45.86(6.79)$

* Data presented as median (range) 


\section{List of Figures}

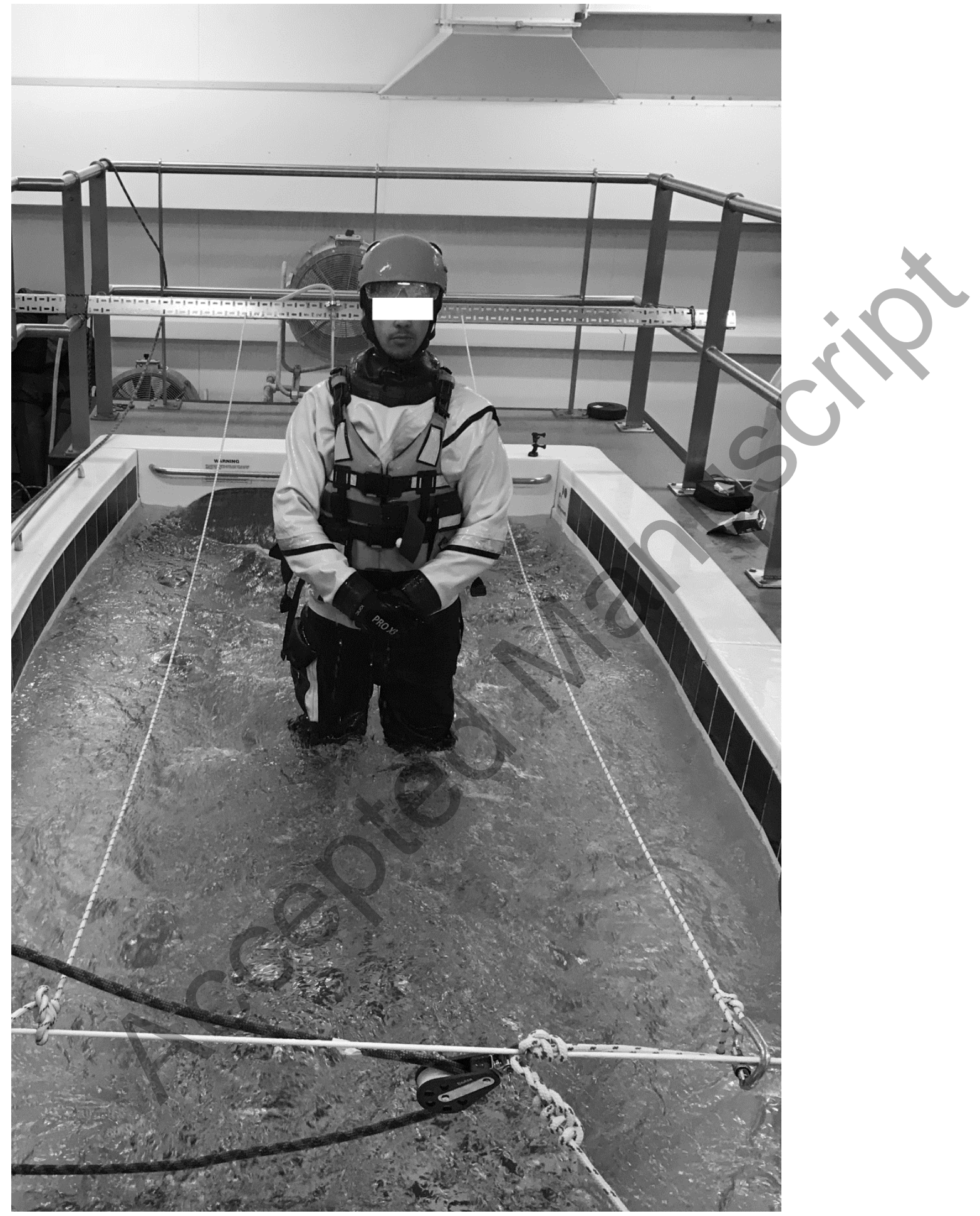

Figure 1. An example of a participant standing in the moving water during the 'Cold' simulation. 


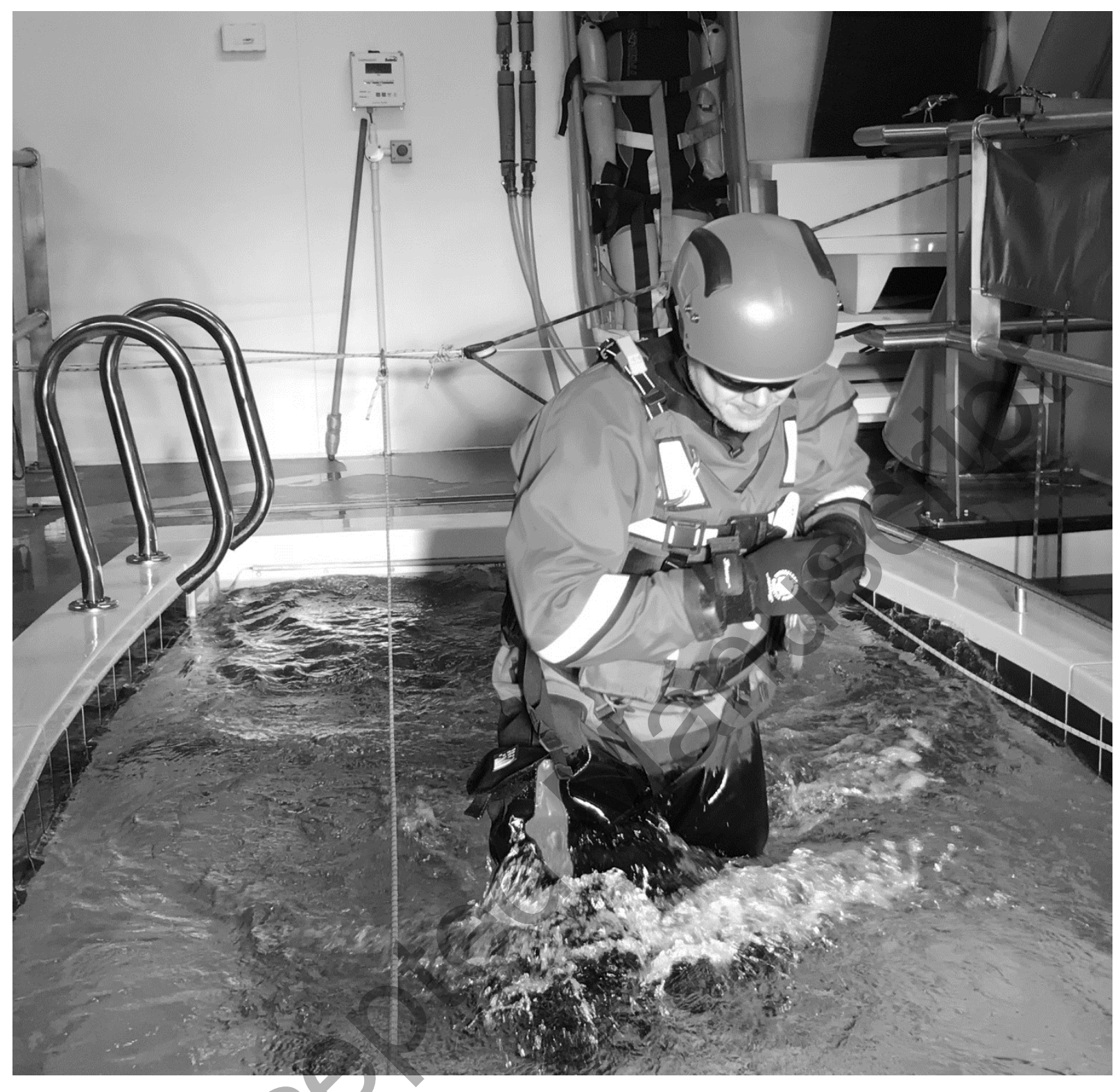

Figure 2. An example of a participant pulling the $10 \mathrm{~kg}$ load into the flow of the water during the 'Warm' simulation. 


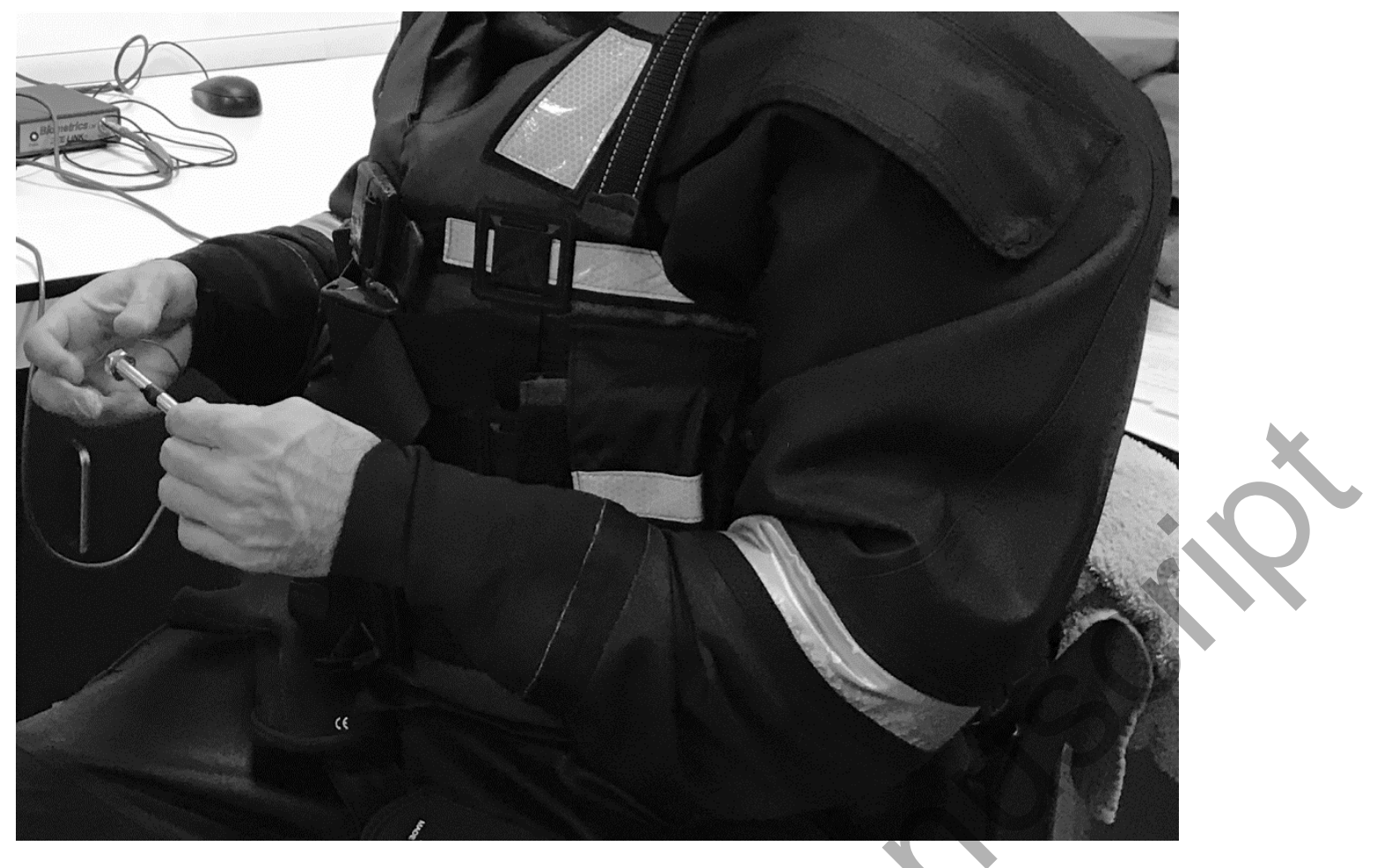

Figure 3. The nut and bolt task. 


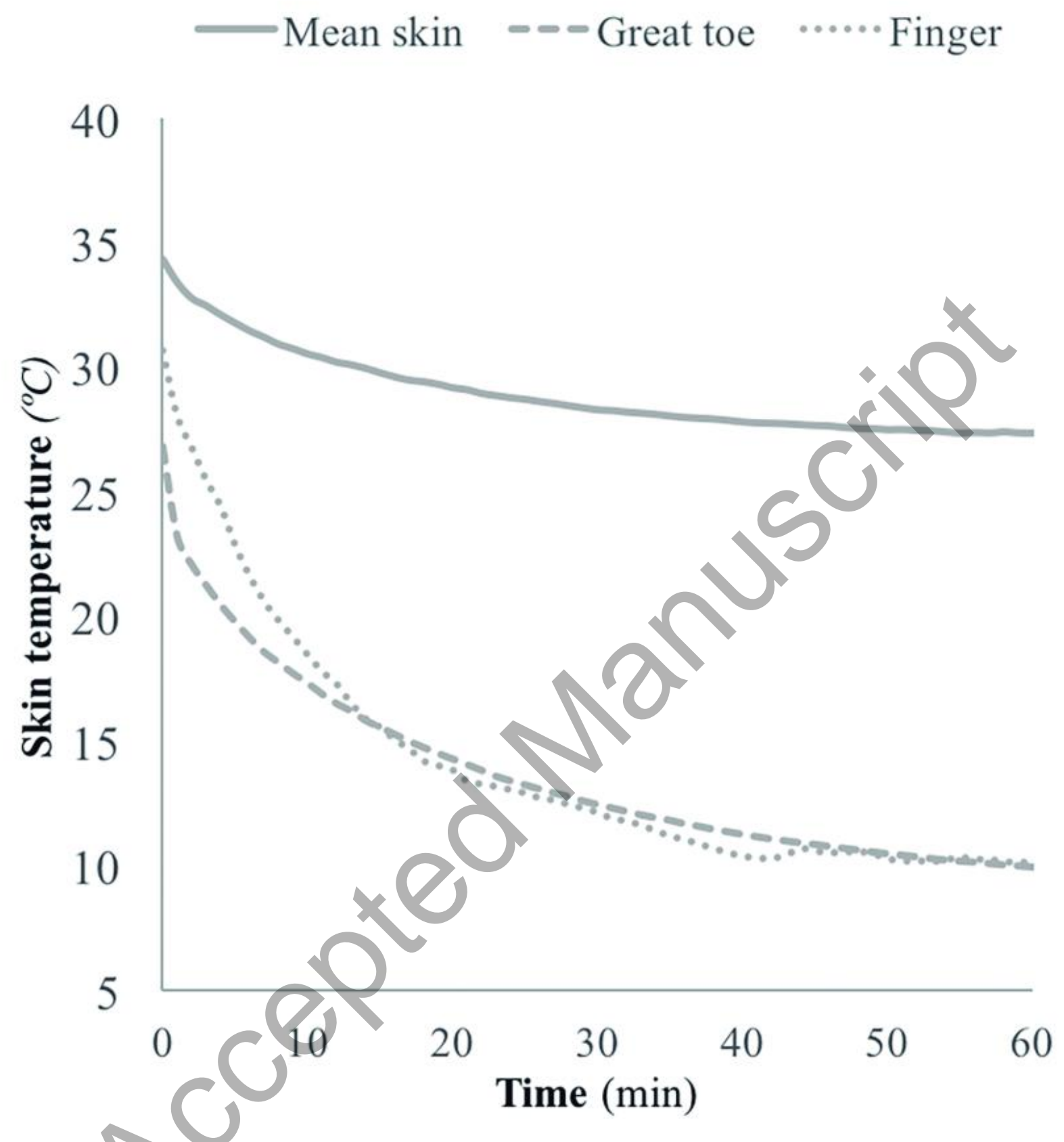

Figure 4. Mean skin, great toe and finger temperature $\left({ }^{\circ} \mathrm{C}\right)$ during the 'Cold' simulation. Note: Standard deviations are omitted for clarity $(n=10)$. 
$\longrightarrow$ Tre $-\infty$ HR

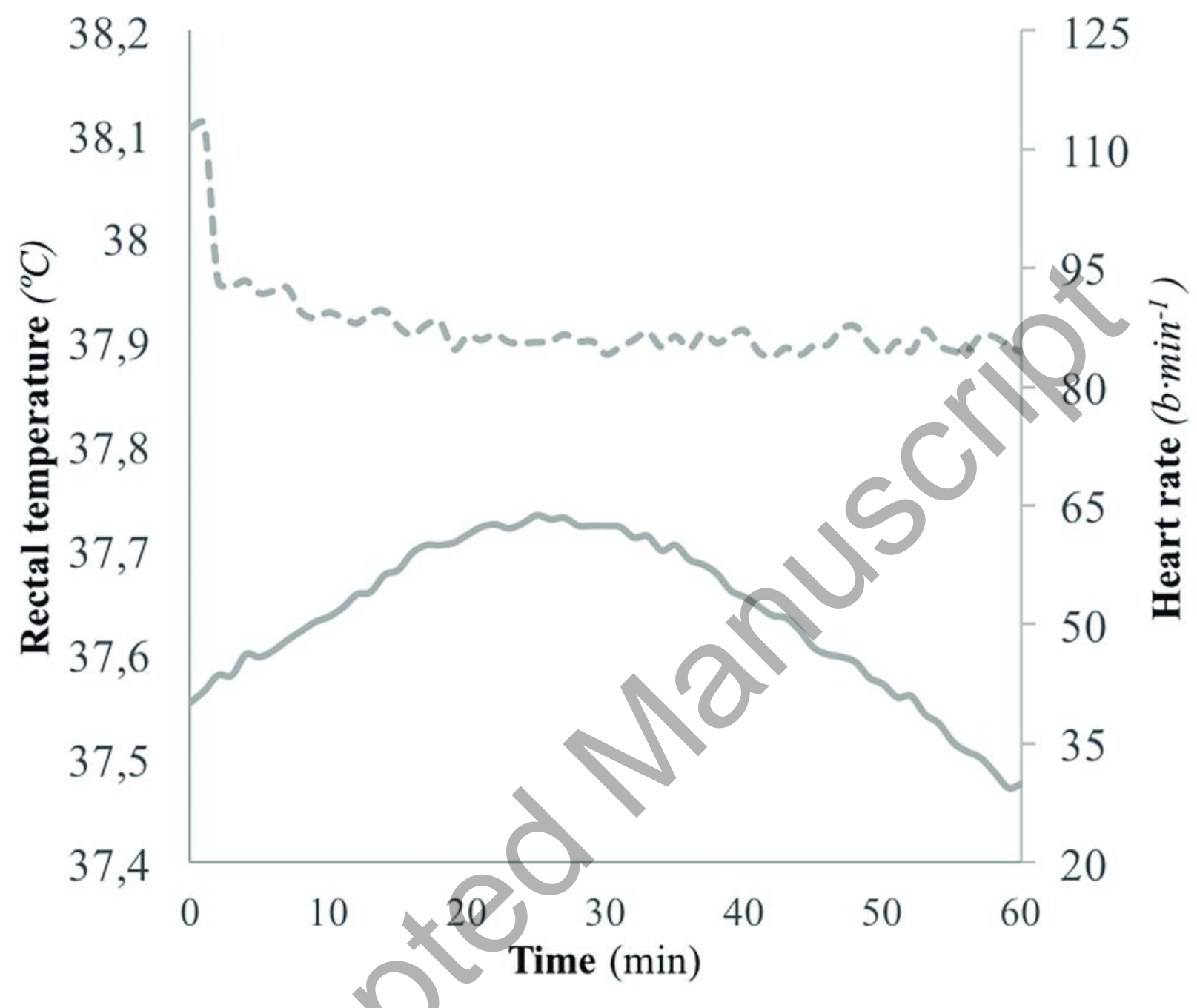

Figure 5. Tre $\left({ }^{\circ} \mathrm{C}\right)$ and heart rate $\left(\mathrm{b} \cdot \mathrm{min}^{-1}\right)$ during the 'Cold' simulation. Note: Standard deviations are omitted for clarity $(\mathrm{n}=10)$. 


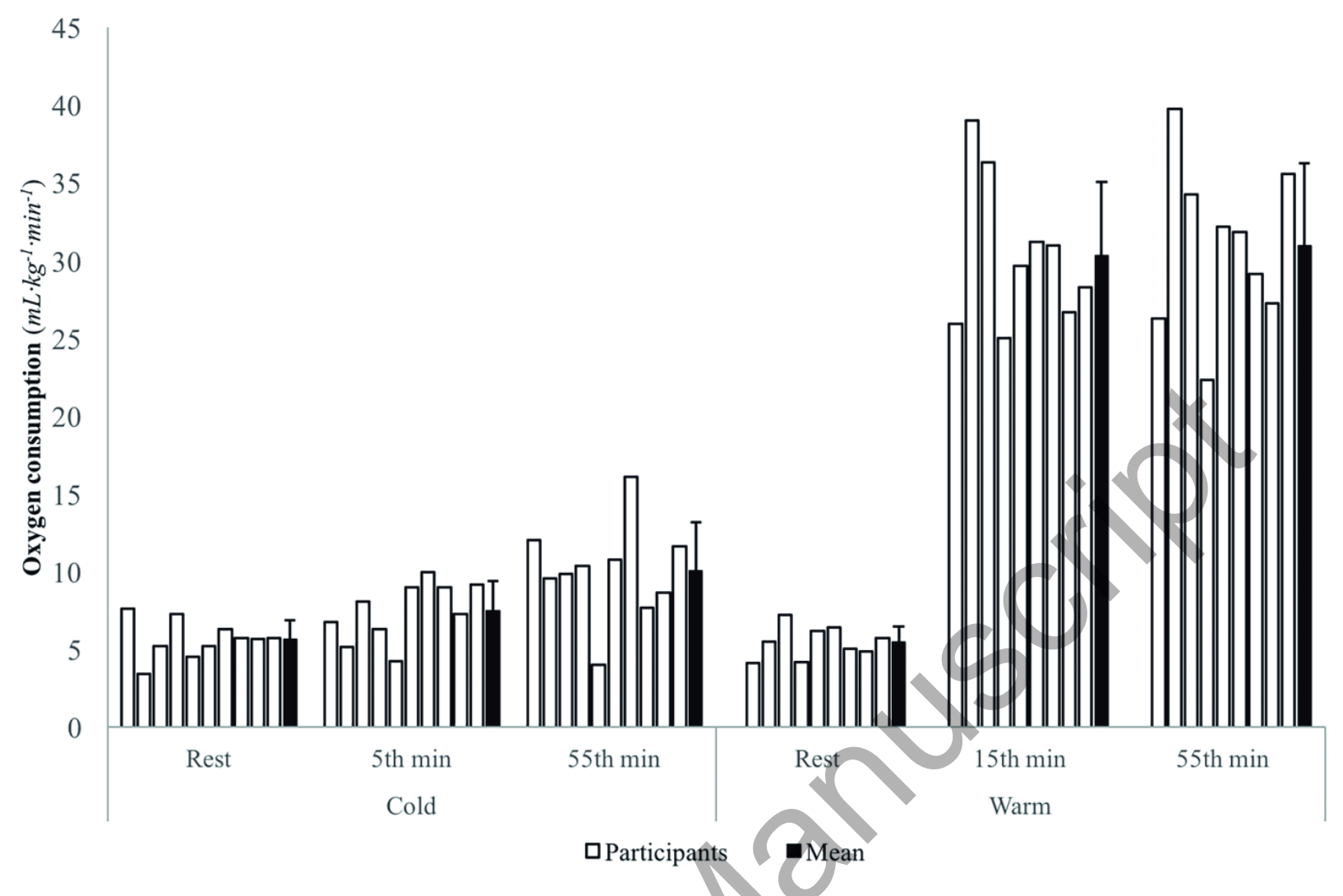

Figure 6. Oxygen consumption ( $\left.\mathrm{mL} \cdot \mathrm{kg}^{-1} \cdot \mathrm{min}^{-1}\right)$ for both the 'Cold' and 'Warm' simulations. Oxygen consumption is presented for each participant (white columns) and mean (SD [black columns]) ( $\mathrm{n}=10)$. 


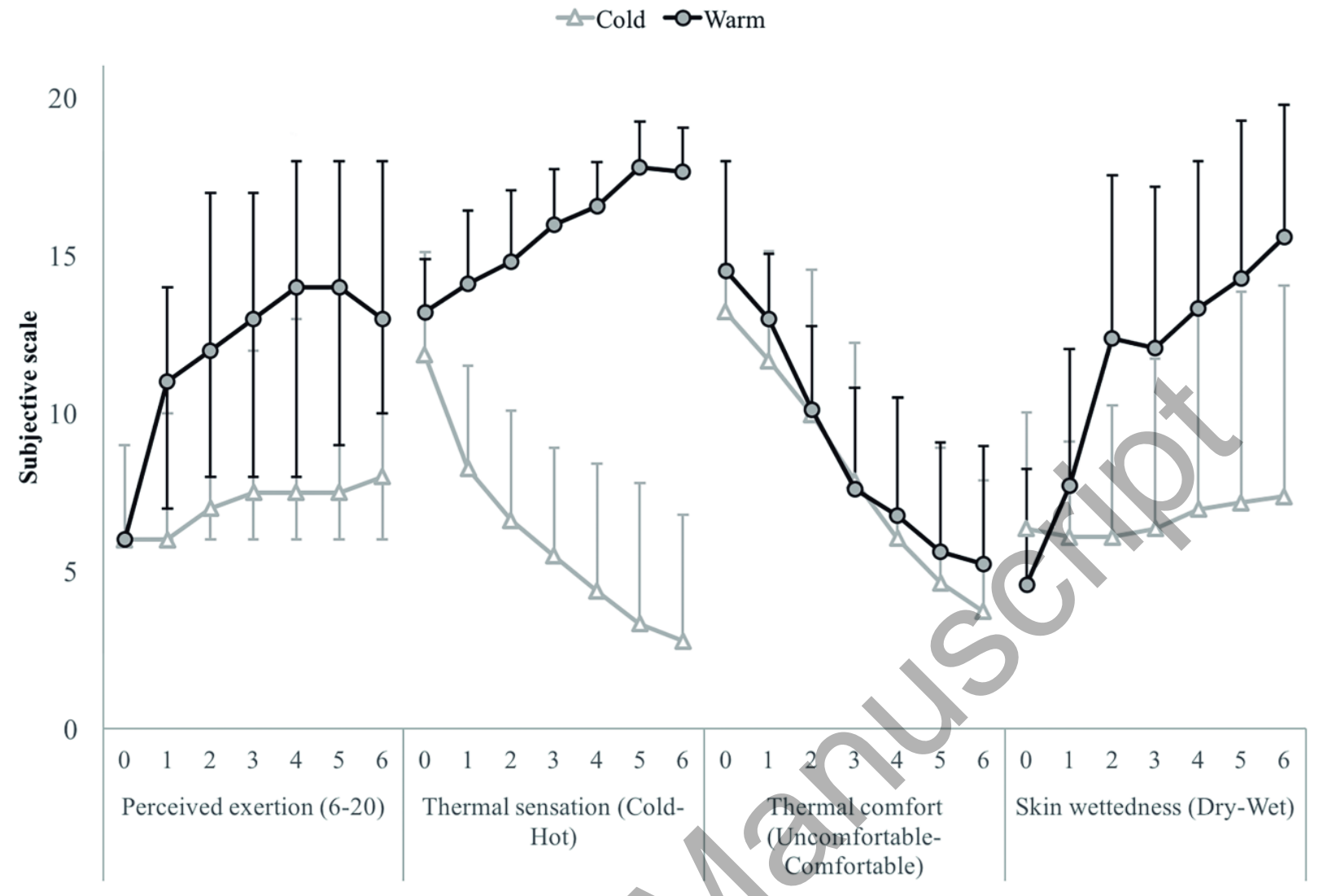

Figure 7. Rate of perceived exhaustion (median [range]), thermal sensation and skin wettedness (mean [SD]) for the start and on completion of exercise during the 'Cold' $(n=10)$ and the 'Warm' simulation $(n=9)$. 


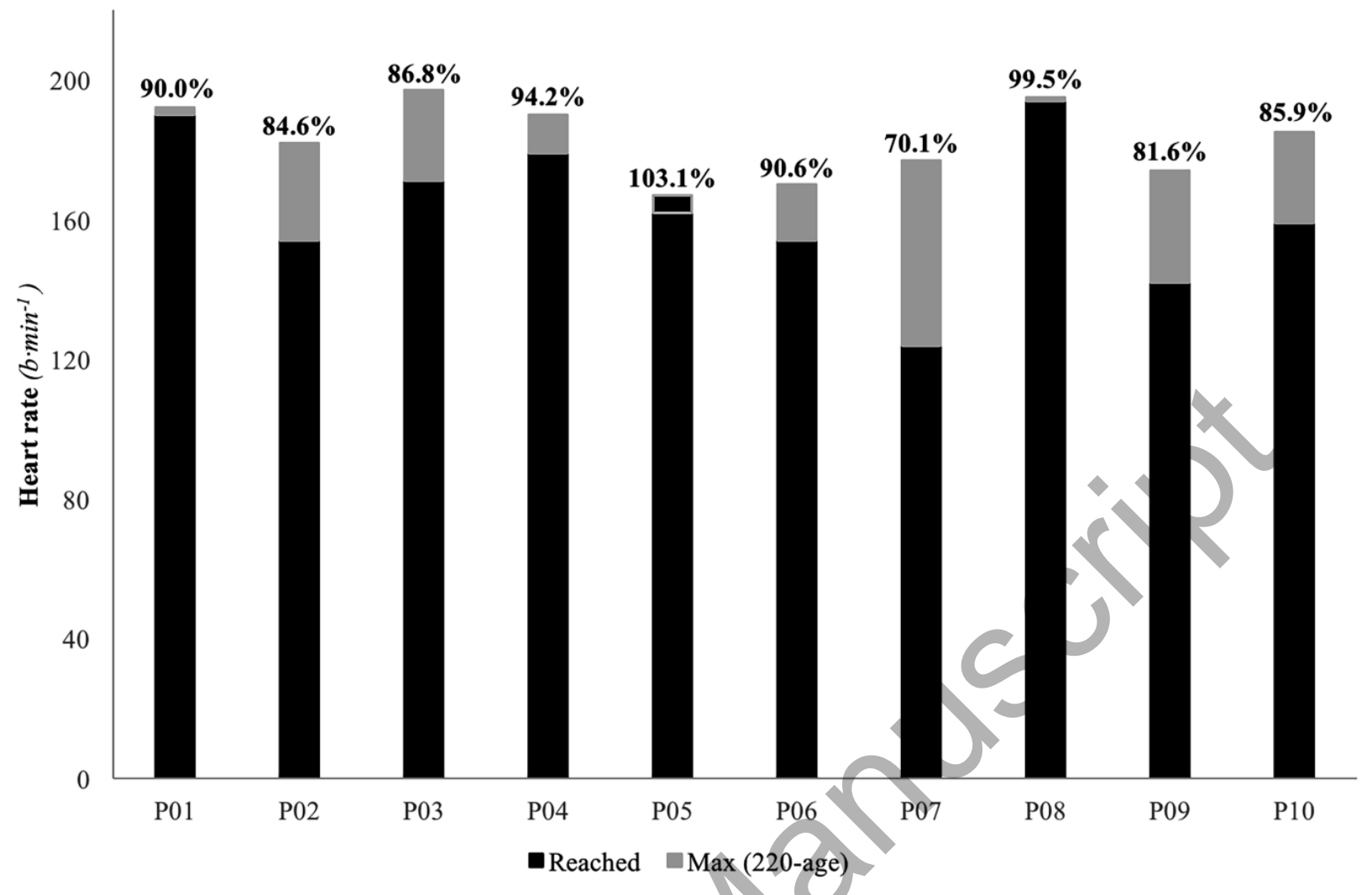

Figure 8. Peak heart rates observed (black columns) against predicted maximum HR (grey columns $[\mathrm{HRmax}=220-$ age $]$ ) during the 'Warm' simulation $(\mathrm{n}=10)$. 


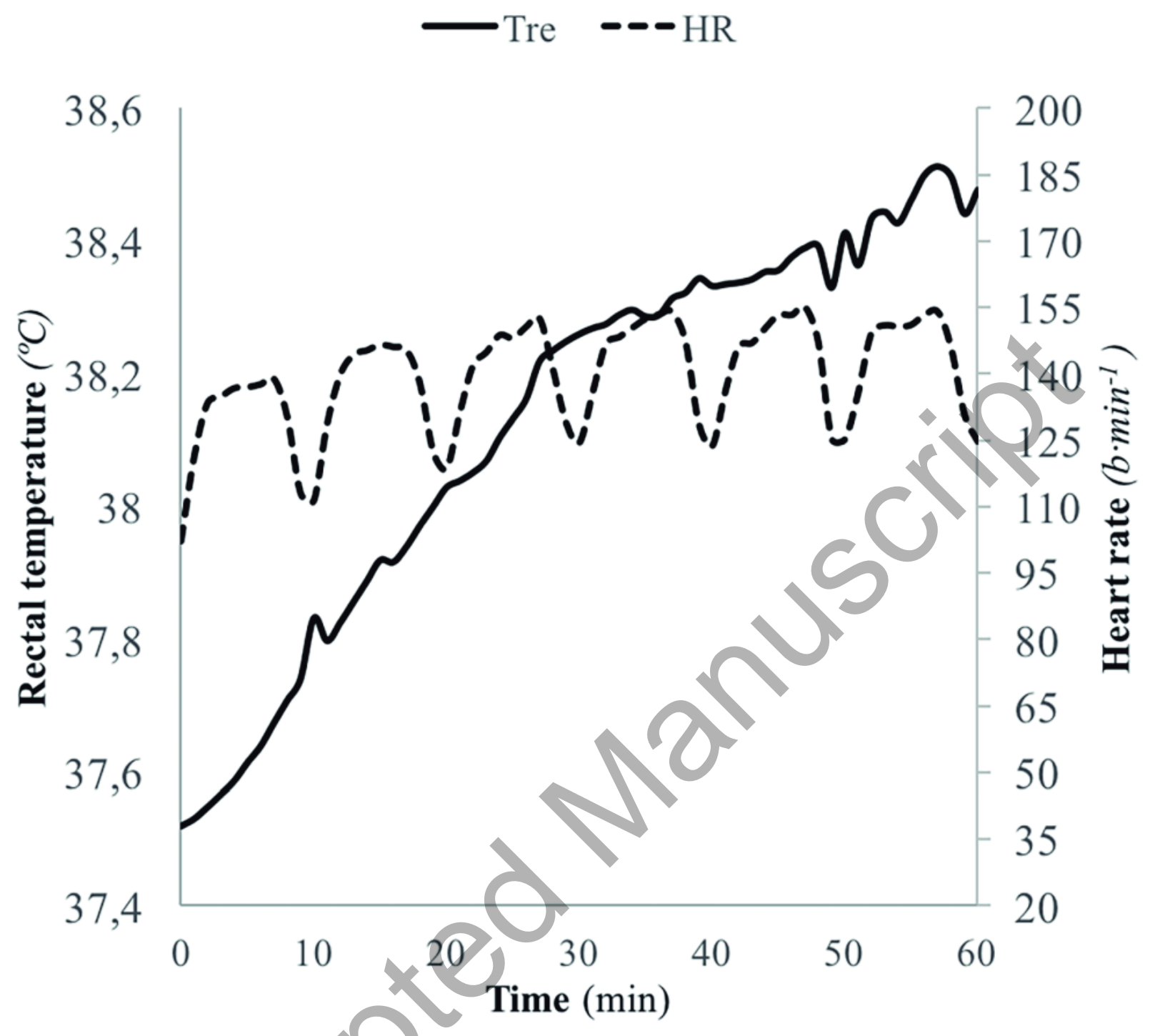

Figure 9. Tre and heart rate per minute during the 'Warm' simulation. Note. Standard deviations are omitted for clarity $(\mathrm{n}=10)$. 